\title{
Decision-Making Biases and Employability: The Mediating Effect of Psychological Capital
}

\author{
Kang Wei ${ }^{1,2}$, Ye Kai ${ }^{3}$, Fu Guifang ${ }^{4 *}$ \\ ${ }^{1}$ Faculty of Business Administration, University of Macau \\ ${ }^{2}$ The Macau University of Science and Technology Foundation- University Hospital \\ ${ }^{3}$ Students' Affairs Division, Guangdong University of Foreign Studies, Canton, China \\ ${ }^{4}$ Department of Applied Psychology, School of Public Administration, Guangdong University of Foreign \\ Studies, Canton, China
}

*Corresponding Author: $\boldsymbol{F u}$ Guifang, Department of Applied Psychology, School of Public Administration, Guangdong University of Foreign Studies, Canton, China

\begin{abstract}
To explore the relationships among psychological capital, decision-making biases and employability of college student and the role of psychological capital between decision-making biases and employability the Scale of college students' Psychological Capital, the Self-assessment Scale of Employability and Decision-making Biases Questionnaire were used to access 312 students. By randomly cluster sampling from Chinese college students $(N=312)$ and by SPSS 24.0 statistics tool this study found the results: 1 . There was significant positively correlation between psychological capital and employability; 2. There was slightly negative relationship between decision-making biases and employability, but the interaction effect between psychological capital and decision-making biases was significantly stronger; 3. The male had higher level of psychological capital and decision-making biases than the female; the higher school year students had better performance in psychological capital, employability, and decision-making biases as well; students majoring in humanity made decision biases more easily than those in sciences; 4. Financial conditions had significantly positive correlation with psychological capital, employability and decision-making biases respectively; academic ranking was positively related to psychological capital and employability; interpersonal communication skill was positively related to psychological capital and employability respectively. 5 . Psychological capital fully mediated between decision-making biases and employability. Career preparation will be the further studies' directions. Conclusion and future studies conclude the article.
\end{abstract}

Keywords: psychological capital, decision-making biases, employability, college students, mediating effect

\section{INTRODUCTION}

College students' employability is the core concern for society and college. It is defined as the comprehensive abilities and traits needed for employment and career development of college students. College students that have higher self-efficacy, higher achievement motivation and lower decisionmaking biases state on their career are easier to make their employment success. In the period of jobhunting and career development, psychological capital (self-efficacy, emotional intelligence and achievement motivation) plays an important role to make employment success, and is related to work performance, turnover rate, well-being, commitment, and satisfaction as well. For poor decisions of their career, the related problems occur in their following time of career development, such as resignation, lower satisfaction and well-being level, bad performance and commitment resulting from regret or passive states. The Positive psychological capital (self-efficacy, hope, optimism and resilience) has significant positive relationship with performance and satisfaction among workers in USA (Luthans, 2007). Further relationships among psychological capital, decision-making biases and employability of college students are motivated to study.

Mainly in terms of judgment and evaluation of information source, there were three types heuristics of decision-making biases as representative heuristic, availability heuristic, and anchoring and adjustment heuristic. Psychological capital is defined as the general psychological abilities, which can representative person's overall psychological resources (Luthans, 2004). Psychological capital is 
related closely to decision-making biases and employability. The hypothesis is that there is the mediating effect of psychological capital. The following is all around the hypothesis. As the research of relationships among emotional intelligence, cognitive intelligence, personality and decision-making biases (Geng, 2008), the emotional intelligence was significantly related to decision-making biases. And over-confidence had significantly influenced on decision-making biases. There was strong relationship between self-efficacy and emotional intelligence and employability as well (Lv, 2012). In this study, the dimensions of psychological capital were emotional intelligence, self-efficacy and achievement motivation, and the key facts of decision-making biases are emotional intelligence and over-confidence (self-efficacy), and the components of employability are self-development capability, interpersonal communication skill, employment confidence, practical ability and adaptability. By viewing these facts, it can be found the mediating effect of psychological capital between decisionmaking biases and employability.

There are lot of facts influencing employability of college students, like it five components of selfdevelopment capability, interpersonal communication skill, employment confidence, practical ability and adaptability (Lv, 2012), and academic performance (Jia, 2007) and parenting way (Wang, 2012), and psychological capital (Li, 2011). According to the phenomenon that for Chinese college students, the higher self-efficacy and achievement motivation, the easier to make employment success, and the results from informed studies on workers, the relationships among psychological capital, decisionmaking biases and employability on college students are waited indeed to be figured out as soon as possible. Comprehensive employability is the basic abilities for them to find a job and keep it, while for employability there are two important facts, decision-making biases and psychological capital. Study suggested that decision-making biases are including inertia, overconfidence and illusion of control and so on (Ya-Ching Lee etc., 2014). Study found that experienced professionals students and non-experienced students made the similar mistakes when dealing with the uncertainty of cyber incidents, but experienced subjects were better able to learn the need for proactive decision-making by an iterative process (Mohammad S. Jalali etc., 2019). During seeking a job and developing their career, the decision-making is vital fact to college students' career and future, and all the way psychological capital can play an important role to make their career development better with powerful psychological resources. Research showed that there were stable and reliable individual differences in rational thinking (Andrea Ceschi, etc., 2019) If finding out their conditions and relationships among these variables, we can take measurements and conduct projects in college and society for students to improve their core competitiveness of employment and career development.

And as far as everyone's personal life, it will be easier to go through without too much dissatisfaction and complaint. For employees, the life can be improved, and the unemployment rate can be reduced down in a better employment market. Also, for development of talent market in China it will work better with the competitive students, in the future China can improve its world statue by the powerful competitiveness of talents in high-tech and fast-going times.

The core value of this study is to look at college students' employability and career development through a new view, and to realize clearly their employability conditions or problems then make measurements to improve their employability efficiently in terms of psychological capital and decision-making biases. And the process of this study is firstly to measure college students' psychological capital state and decision-making biases levels. Then explain the fact of their employability in college and find the correlation relationships among these variables. And examine interaction effect or the equation by regression analysis and model fitting. The mediating effect and moderating effect of psychological capital and decision-making biases will be analyzed in this study. To conduct projects pointing at the suitable target, the difference of psychological capital, decisionmaking biases and employability by population variables should be examined and analyzed, like the background information of participants as gender, grade, birthplace, parenting styles, single parent family, only child family, financial conditions and academic rankings.

\section{METHODS}

\subsection{Participants}

The participants were the college students $(\mathrm{N}=312$, Male=115; Female=197) who came from eight classes, four grade in different department. 
Table1: Participants' demographic variables $(N=312)$

\begin{tabular}{|c|c|c|c|c|c|c|c|}
\hline \multirow{3}{*}{\multicolumn{2}{|c|}{ Gender }} & & & & & $N$ & Frequency (\%) \\
\hline & & & & & Male & 115 & 36.9 \\
\hline & & & & & Female & 197 & 63.1 \\
\hline \multirow{2}{*}{\multicolumn{2}{|c|}{ Birthplace }} & & & & Town/City & 185 & 59.3 \\
\hline & & & & & Countryside & 127 & 40.7 \\
\hline \multirow{2}{*}{\multicolumn{2}{|c|}{ Only-Child }} & & & & Yes & 112 & 35.9 \\
\hline & & & & & No & 200 & 64.1 \\
\hline \multirow{4}{*}{\multicolumn{2}{|c|}{ Grade }} & & & & First-School-Year & 174 & 55.8 \\
\hline & & & & & Second-S-Y & 82 & 26.3 \\
\hline & & & & & Third-S-Y & 56 & 17.9 \\
\hline & & & & & Fourth-S-Y & 0 & \\
\hline \multirow{5}{*}{\multicolumn{2}{|c|}{ Major }} & & & & Humanity & 135 & 43.3 \\
\hline & & & & & Science & 139 & 44.6 \\
\hline & & & & & Engineer & 9 & 2.9 \\
\hline & & & & & Arts & 7 & 2.2 \\
\hline & & & & & Others & 22 & 7.0 \\
\hline \multirow{3}{*}{\multicolumn{2}{|c|}{$\begin{array}{l}\text { Financial } \\
\text { conditions }\end{array}$}} & & & & Poor & 36 & 11.5 \\
\hline & & & & & Middle & 255 & 81.7 \\
\hline & & & & & Rich & 21 & 6.7 \\
\hline \multirow{4}{*}{\multicolumn{2}{|c|}{$\begin{array}{l}\text { Parenting } \\
\text { styles }\end{array}$}} & & & & Doting & 13 & 4.2 \\
\hline & & & & & Democratic & 214 & 68.6 \\
\hline & & & & & Authoritarian & 31 & 9.9 \\
\hline & & & & & Laissez-faire & 54 & 17.3 \\
\hline \multirow{2}{*}{\multicolumn{2}{|c|}{$\begin{array}{l}\text { Single } \\
\text { parent }\end{array}$}} & & & & Yes & 19 & 6.1 \\
\hline & & & & & No & 293 & 93.9 \\
\hline \multirow{2}{*}{\multicolumn{2}{|c|}{$\begin{array}{l}\text { Been } \\
\text { leader }\end{array}$}} & & & & Yes & 246 & 78.8 \\
\hline & & & & & No & 66 & 21.2 \\
\hline \multirow{5}{*}{\multicolumn{2}{|c|}{$\begin{array}{l}\text { Academic } \\
\text { ranking }\end{array}$}} & & & & Much-lower & 4 & 1.3 \\
\hline & & & & & Lower & 21 & 6.7 \\
\hline & & & & & Middle & 116 & 37.2 \\
\hline & & & & & Higher & 144 & 46.2 \\
\hline & & & & & Top & 27 & 8.7 \\
\hline \multirow{3}{*}{\multicolumn{2}{|c|}{$\begin{array}{l}\text { Interpersonal } \\
\text { skills level }\end{array}$}} & & & & Poor & 8 & 2.6 \\
\hline & & & & & General & 210 & 67.3 \\
\hline & & & & & Good & 94 & 30.1 \\
\hline
\end{tabular}

\subsection{Measurements}

The completed questionnaire and scale came out including four parts with 73 items totally, the first part with basic and background information questions with 11 items, such as gender, grade, academic ranking and interpersonal communication skill and so on. The other three parts were the Scale of college students' Psychological Capital, Decision-making Biases Questionnaire and Self-assessment Scale of college students' Employability.

\subsubsection{The Scale of College Students' Psychological Capital}

The scale was revised by Jiang Suqin (2012). Psychological capital is measured as the overall contribution from self-efficacy, emotional intelligence and achievement motivation. And all items (23 items) used Likert-type five point scales with responses from 1 (strongly disagree) to 5 (strongly agree). Self efficacy part has 7 items, like "if I try my best to address this problem, it always can be made" and "I believe all difficulties can be overcome"; emotional intelligence part contains six items, such as "I can understand others' nonverbal communication information" and "when others are upset or down I can cheer them up"; and the third part for achievement motivation with ten items, items like "I like the challenging and novel work even go with risks". The scale has been examined having high internal consistency reliability in this study (overall Cronbach's alpha coefficients $=0.905$ ).

\subsubsection{Decision-Making Biases Questionnaire (DDQ)}

This questionnaire was revised by Lv Zhaohua (2012) and it is including with 13 items by three 
dimensions of representative heuristics, availability heuristic, and anchoring and adjustment heuristic. And every item is with the true or false multiple choices question. If respondents choose the right answer they will get 0 score; if choose the wrong answer they will get 2 scores as the 2 value. And specially in the sixth item it is the combined questions with one result, which means if participants give the answer in the second question of sixth item is more than the first one they will get 2 scores, or 0 score. The overall Cronbach's alpha coefficients was 0.840 .

\subsubsection{Self-Assessment Scale of College Students' Employability (SSE)}

The scale was revised by Lv Zhaohua (2012) and it has 26 items with five employability components of self-development capability, interpersonal communication skill, employment confidence, practical ability and adaptability. All employability items used Likert-type five point scales with responses from 1 (strongly disagree) to 5 (strongly agree). For example, the component of self-development capability, there are 7 items to measure, like "I always learn and gain the new knowledge quickly around me" and "I always keep fighting for the goal I decided". The Cronbach's alpha coefficient of this scale was 0.884 .

\subsection{Data Analysis}

Using SPSS 24.0 statistic software to analyze the data of the Scale of college students' Psychological Capital, the Self-assessment Scale of college students' Employability and Decision-making Biases Questionnaire, get the results. Through Description Statistics, Correction analysis and LinearRegression analysis and Sobel test, R-value and Reliability are figured out by T-test and ANOVA analysis. And interaction effect is figured out as well. Mediating effect and moderating effect of psychological capital and decision-making biases are analyzed through regression by PROCESS.

\section{ReSUlts}

\subsection{Descriptive Statistics}

The results of decision-making biases indicated that mean difference among participants was significant at the 0.001 level by T-test; overall mean value was 14.78 more than 13 (the perfect value is 26), which showed that participants had high decision-making biases level; compared with the three heuristics' mean value, anchoring and adjustment heuristics (MAAH=5.47, Nitem=4) had highest mean value among the three ones $(\mathrm{MAH}=4.23$, Nitem=4), but the representative heuristic was lowest one $(\mathrm{MRH}=4.89$, Nitem=5), which claimed that college students as the samplers in this study more easily to make decision-making biases through anchoring and adjustment heuristics model and not through representative heuristic.

Table2: Description statistic

\begin{tabular}{|l|l|l|l|l|l|}
\hline & \multicolumn{1}{|c|}{$\boldsymbol{d f}$ (valid) } & \multicolumn{1}{|c|}{ Nof item } & \multicolumn{1}{|c|}{ Mean } & \multicolumn{1}{c|}{$\boldsymbol{\text { SD }}$} & \multicolumn{1}{c|}{$\boldsymbol{t}$} \\
\hline $\begin{array}{l}\text { Psychological } \\
\text { capability }\end{array}$ & 311 & 23 & 80.23 & 11.584 & $122.340 * * *$ \\
\hline Employability & 311 & 26 & 91.43 & 11.119 & $145.242 * * *$ \\
\hline $\begin{array}{l}\text { Decision-making } \\
\text { Biases }\end{array}$ & 311 & 13 & 14.78 & 3.873 & $67.415^{* * *}$ \\
\hline
\end{tabular}

***. Mean difference is significant at the 0.001 level.

The mean value of overall variance from employability was $91.43(91.43>26 * 3)$ and significant at the 0.001 level, which indicated that average level of college student was higher than the standard average level $(26 * 3=78)$. Among the five components, the mean level ranking of them from high to low order was in sequence interpersonal communication skill $(\mathrm{M} 1=18.38, \mathrm{~N} 1=5)$, self-development, employment confidence (M3=17.49, N3=5), practical ability and adaptability (M5=13.58, N5=4). The adaptability was the lowest component contributor to the overall variance, and college and students themselves should pay attention and effort to develop adaptability in order to develop their employability well.

\subsection{The Difference Analysis}

The mean difference of academic ranking (AR), interpersonal communication skill (ICS), psychological capital (PC), decision-making biases (DD) and employability (EA) classified by gender, grade, major, birthplace, only-child, single-parent, parenting style, and financial condition were in table 3. 
Table3: Difference analysis $(d f=311)$

\begin{tabular}{|l|l|l|l|l|l|}
\hline & \multicolumn{1}{|c|}{ AR } & \multicolumn{1}{c|}{ ICS } & \multicolumn{1}{c|}{ PC } & \multicolumn{1}{c|}{ DD } & \multicolumn{1}{c|}{ EA } \\
\hline Gender & 3.301 & $5.896^{*}$ & $9.260^{* *}$ & $26.011^{* * *}$ & 1.965 \\
\hline Grade & $3.861^{*}$ & $10.603^{* * *}$ & $8.200^{* * *}$ & $6.407^{* *}$ & $5.477 * *$ \\
\hline Major & $2.945^{*}$ & $3.122^{*}$ & 0.898 & $3.105^{*}$ & 2.374 \\
\hline Financial condition & $8.826^{* * *}$ & $14.115^{* * *}$ & $7.408^{* * *}$ & $3.516^{*}$ & $4.572^{*}$ \\
\hline Academic ranking & 1.00 & $9.012^{* * *}$ & $7.637 * * *$ & 1.308 & $9.498^{* * *}$ \\
\hline ICS & $9.012^{* * *}$ & 1.00 & $48.052^{* * *}$ & 2.179 & $47.495^{* * *}$ \\
\hline
\end{tabular}

$* \mathrm{p}<0.05, * * \mathrm{p}<0.01, * * \mathrm{p}<0.001$, PC as Psychological capital; DD as decision-making biases; EA as employability; CPA as career preparation accomplishment. AR as academic ranking; ICS as interpersonal communication skill.

PC was significant of mean difference by gender, grade, financial condition, academic ranking and interpersonal communication skill. Male college students had higher psychological capital than female's; and the higher of the grade, the higher of psychological capital state level, the same of financial condition, academic ranking and interpersonal communication skill. Employability was significant different from grade, financial condition, academic ranking and interpersonal communication skill. The higher of grade, financial conditions, AR and ICS level, the higher of employability level. Decision-making biases's was significant by gender, grade, major, financial condition. Male college students were more easily with biases of decision-making.

\subsection{Correlation among Psychological Capital, Decision-Making Biases, Academic Ranking, Interpersonal Communication Skill and Employability}

Table 4 was Pearson Correlation analysis (two-tailed) of psychological capital, decision-making biases, academic ranking, interpersonal communication skill, and employability under control variables of population related background factors of participants (gender, grade, major, parenting styles, only child, single parent, and financial condition.

Table4: Correlations analysis

\begin{tabular}{|l|l|l|l|}
\hline & PC & DD & EA \\
\hline PC & 1.000 & & \\
\hline DD & $-0.177^{* *}$ & 1.000 & \\
\hline EA & $0.76^{* *}$ & $-0.122^{*}$ & 1.000 \\
\hline
\end{tabular}

${ }^{*} \mathrm{p}<0.05, * * \mathrm{p}<0.01$.

There was significantly positive relationship between psychological capital and employability $(\mathrm{r}=0.76)$. And psychological capital was negative related to decision-making biases $(\mathrm{r}=-0.177)$. Employability was slightly negative correlation with decision-making biases significantly ( $r=-0.122)$.

Decision-making biases and psychological capital as two dependent variables effected employability. Interaction effect analysis and correlation analysis was in table 5.

Table5: Interaction effect analyses

\begin{tabular}{|l|l|l|l|}
\hline & PC & DD & PC*DD \\
\hline EA & $0.76^{* *}$ & $-0.116^{*}$ & $0.259^{* *}$ \\
\hline
\end{tabular}

$* \mathrm{p}<0.05, * * \mathrm{p}<0.01$

The interaction effect of PC and DD was highly significant ( $r=0.259)$. Firstly the correlation between psychological capital and employability was 0.76 , and the correlation of decision-making biases and employability was only 0.116 , and interaction effect $(r=0.259)$ between psychological capital and decision-making biases was stronger than decision-making biases and employability separately correlation $(\mathrm{r}=0.116)$.

\subsection{The Moderating Effect and Mediating Effect}

Table6: Regression model analysis

\begin{tabular}{|c|c|c|c|c|}
\hline $\begin{array}{c}\text { Independent } \\
\text { Variables (predictors) }\end{array}$ & $\mathbf{R}^{2}$ & $\begin{array}{c}\text { Std. Coefficients } \\
\text { Beta }\end{array}$ & $\mathbf{F}$ & $\mathbf{t}$ \\
\hline $\mathrm{PC}$ & 0.605 & 0.778 & $475.72 * * *$ & \\
\hline
\end{tabular}




\begin{tabular}{|c|c|c|c|c|}
\hline DD & 0.015 & -0.122 & $4.71 *$ & \\
\hline PC*DD & 0.067 & 0.259 & $22.25 * * *$ & \\
\hline AR & 0.106 & 0.325 & $36.69 * * *$ & \\
\hline Whole Model & 0.621 & 0.788 & $125.63 * * *$ & \\
\hline $\mathrm{PC}$ & & 0.809 & & $6.294 * * *$ \\
\hline DD & & 0.088 & & 0.353 \\
\hline PC*DD & & -0.045 & & 0.176 \\
\hline
\end{tabular}

$* \mathrm{p}<0.05, * * * \mathrm{p}<0.001$, Dependent variable is as employability.

Table 6 showed that correlation was significantly and high positively between PC and EA, PC*DD and EA, AR and EA; DD and EA as negatively correlation. That means that the PC, DD, PC*DD and AR could predict EA highly as contributors. Model structure was EA=0.749PC-0.035DD+ $0.013 \mathrm{PC} * \mathrm{DD}+0.121 \mathrm{AR}+\mathrm{e}$, and it was different from the contribution value of these factors separately as the only factor to contribute employability, such as the value of psychological capital by employability in the whole model was as 0.749 not 0.778 ; which showed that the DVs under model construction were impacted by each other. However for specific model construction or career development of college students could be like this, which will be studies in the future research about college students' employability and career preparation.

And by the interaction effect (PC*DD) of psychological capital and decision-making biases, the moderating effect between psychological capital and decision-making biases was not significant by the value of $\mathrm{t}(\mathrm{r}=-0.045, \mathrm{t}=-0.176)$. Further study should be focused on it.

Table7: Mediating effect analysis of psychological capital

\begin{tabular}{|l|l|l|l|l|}
\hline & \multicolumn{1}{|c|}{ Std. Regression equation } & \multicolumn{1}{c|}{ Std. Error } & \multicolumn{1}{c|}{$\boldsymbol{T}$} & \multicolumn{1}{c|}{$\boldsymbol{R}$} \\
\hline The First step & $\mathrm{y}=-0.122 \mathrm{x}+\mathrm{e}_{1}$ & 0.162 & $-2.172^{*}$ & $-0.122^{*}$ \\
\hline The Second step & $\mathrm{m}=-0.212 \mathrm{x}+\mathrm{e}_{2}$ & 0.019 & $-3.820^{* * *}$ & $-0.212^{* * *}$ \\
\hline The Third step & $\mathrm{y}=0.788 \mathrm{~m}-0.045 \mathrm{x}+\mathrm{e}_{3}$ & 0.105 & 1.223 & $0.788^{* * *}$ \\
& & & & -0.045 \\
\hline
\end{tabular}

$* . \mathrm{p}<0.05, * * * . \mathrm{p}<0.001$
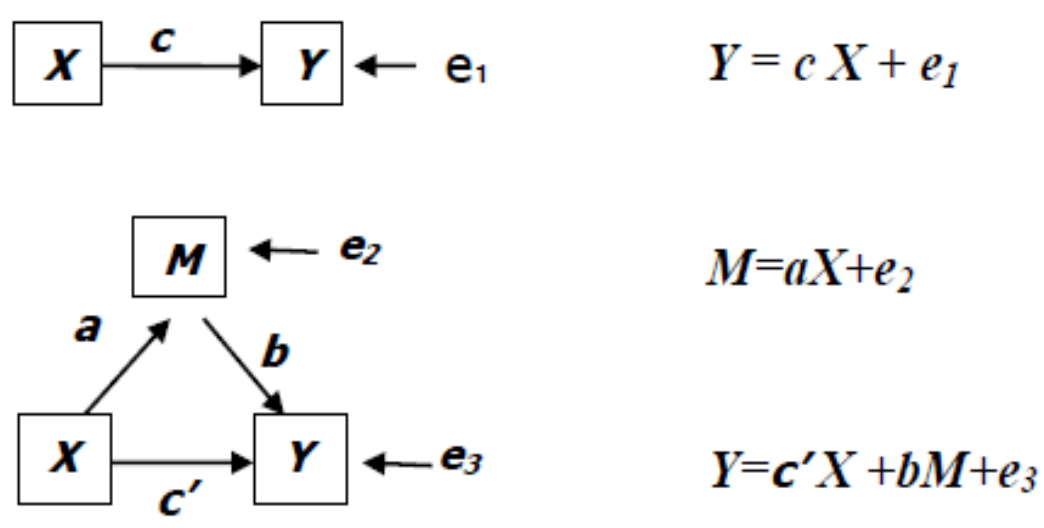

According to Wen's (2004) research of mediating effect analysis model, the value of a $(a=-0.212), b$ $(b=0.788)$, and $c(c=-0.122)$ all were significant and the value of $c^{\prime} \quad\left(c^{\prime}=0.045\right)$ was not significant. All values met the Null hypothesis requirements to examine the significance of mediating effect of psychological capital as Wen's research discussed (2004). Psychological capital had the full mediating effect between decision-making biases and employability. Except the direct impact of decision-making biases on employability, decision-making biases could work on employability through psychological capital's completed mediating effect indirectly.

\section{DISCUSSION}

\subsection{Psychological Capital and Employability}

The results indicated that college students' employability is higher than standard middle value of the scale with significantly difference, similarly as the research results of Lv (2012). Considering the strongly positive correlation between psychological capital and employability, to improve the state of 
college students' PC can help better employability indirectly. For example, to increase chances for college students to experience success and achievement in order to improve the state of self-efficacy, to motivate them by teaching or case studies in classes, or set good model for them to follow. More chances to practice (part-time jobs, internships or volunteers) and experience various circumstances to get the training or development for specific abilities as employability's components directly, like adaptability and practical ability. Enough psychological education and training can lead college students to positively face life and address problems, in this way the emotional intelligence will be developed well. Finally the psychological capital will be built better directly.

\subsection{Decision-Making Biases and Employability}

This study suggested college students' decision-making biases (14.78) is higher than middle standard value (13). College students should pay more effort to improve information source management skill avoiding irrational decisions under gaps between the media (Vladlena Benson, 2014) advertisement or social employment market communication and the fact. Developing well of psychological capital and employability and decision-making biases can improve college students' competitiveness in career development and success. And in this study the correlation of decision-making biases and employability is significantly negative related. Decision-making biases had not only directly impact on employability, but also indirectly impact on employability through psychological capital's full mediating effect. Research showed that the application of EI ability in individual decision-making process can effectively reduce cognitive bias (Walter S. Hersing, 2017). As Simon's theory of decision-making, the questionnaire of decision-making biases should be improved in the future. Because so much content of items made the participants boring and tired and they cannot pay enough attention on them, which influenced the reliability and validity of this questionnaire. The biases can easily occur not only the state of decision makers but also the situations of the process to make decisions.

\subsection{The Mediating Effect}

In this work the full mediating effect was found between decision-making biases and employability by regression analysis and model equations. It illustrated that decision-making biases had indirect impact on employability through psychological capital's significantly full mediating effect, besides decision-making biases' direct impact on employability. This finding was the creative contribution to work for the relationships among decision-making biases, psychological capital, and employability, and the role of psychological capital as well. Up to now there are no few researches on the mediating effect between decision-making biases and employability. However, the moderating effect among psychological capital, decision-making biases and employability was not significant in this study. Maybe they are the sampling or sample or questionnaires or other reasons resulting in no significance. Or there does be no moderating effect among decision-making biases, psychological capital and employability. It is further study directions.

\subsection{Employability and Career Preparation Accomplishment}

As the understanding of employability and its relationships with psychological capital and decisionmaking biases, college student's career development on career preparation level is more valuable to study, such as career preparation accomplishment as the comprehensive generally understanding of college students' accomplishment level on career preparation. It seems like that compared with employability career preparation accomplishment is a kind of broad understanding of college students' career development level. Research showed that young professionals who had developed high levels of career competencies had higher levels of perceived employability (Rowena Blokker etc., 2019). What is career preparation accomplishment of college students is that they should have not only the specific abilities (employability narrowly defined with self-development, interpersonal communication skill, adaptability) needed for employment and career development but also need comprehensive traits (psychological capital) to achieve career goals and keep it going well instead of being fired or frequent job-hopping, and also for the beginning of job-hunting the decision-making biases should be concerned to rationally make a choice of their career development with positions or companies or payment or industries.

Future study should enlarge the size of sampling and participants should cover more university and even other country with multi-culture background. In order to find more evidences the continuous 
following research is needed for 2 years, 5 years or 10 years data collecting about the participants' employability abroad-defined (career preparation accomplishment). Further research should seek to find how college students' career develops, what problems occurred during the process and what the causes are, and how to avoid or address.

\section{ACKNOWLEDGEMENT}

This work was supported by The National Social Science Fund of China [grant number 16BSH094].

\section{REFERENCES}

[1] Andrea Ceschi, Arianna Costantini, Riccardo Sartori, Joshua Weller, Annamaria Di Fabio.(2019). Dimensions of decision-making: An evidence-based classification of heuristics and biases, Personality and Individual Differences, 146, 188-200

[2] Geng Liang. (2008). A study on the relationship between emotional intelligence, cognitive intelligence and personality of college students and decision-making bias. Master's thesis of Shanghai Normal University.

[3] Jia Lijun. (2007). A study on the structure of College Students' employability. Master's thesis of Nanjing Normal University.

[4] Jiang Suqin.(2011). A study on the connotation and structure of College Students' psychological capital. Master's thesis of Nanchang University.

[5] Li Hua, Cao Xingtian. (2011). Research on the relationship between psychological capital and employability of college students. China higher education research, (03): 54-56

[6] Luthans, Fred; Avolio, Bruce J; Avey, James B; Norman, Steven M. (2007). "Positive Psychological Capital: Measurement and Relationship with Performance and Satisfaction”, Personnel Psychology, 60, 3; pg.541.

[7] Luthans, Fred; Avolio, Bruce J; Walumbwa, Fred O; Weixing Li. (2004) "The Psychological Capital of Chinese Workers: Exploring the Relationship with Performance"; University of Nebraska-Lincoln, USA; Management and Organization Review 1:2 249-271; 1740-9776.

[8] Lv Zhaohua. (2012) The correlation research between psychological capital and employment ability of college students. Master's thesis of Guangxi Normal University.

[9] Mohammad S. Jalali, Michael Siegel, Stuart Madnick.(2019). Decision-making and biases in cyber security capability development: Evidence from a simulation game experiment, The Journal of Strategic Information Systems, Volume 28, Issue 1, 66-82.

[10] Rowena Blokker, Jos Akkermans, Maria Tims, Paul Jansen, Svetlana Khapova, Building a sustainable start: The role of career competencies, career success, and career shocks in young professionals' employability, Journal of Vocational Behavior, Volume 112, 172-184

[11] Vladlena Benson, Stephanie Morgan, Fragkiskos Filippaios.(2014). Social career management: Social media and employability skills gap. Computers in Human Behavior, Vol. 30, 519-525

[12] Wang Pengjun. (2012). Relationship between parenting style, psychological capital and academic achievement of college students. Master's thesis of Shandong Normal University.

[13] Walter S. Hersing. (2017). Managing cognitive bias in safety decision making: Application of emotional intelligence competencies, Journal of Space Safety Engineering, Volume 4, Issues 3-4,2017, 124-128,

[14] Wen Zhonglin, Zhang Lei, Hou Jietai, Liu Hongyun. (2004). The test procedure of mediating effect and its application. Acta Psychologica Sinica, (05): 614-620.

[15] Ya-Ching Lee. (2014). Impacts of decision-making biases on eWOM retrust and risk-reducing strategies, Computers in Human Behavior,Volume 40, 101-110.

Citation: Fu Guifang, et al. "Decision-Making Biases and Employability: The Mediating Effect of Psychological Capital" International Journal of Managerial Studies and Research (IJMSR), vol 8, no. 1, 2020, pp. 28-35. doi: http://dx.doi.org/10.20431/23 49-0349.0801003.

Copyright: (C) 2020 Authors. This is an open-access article distributed under the terms of the Creative Commons Attribution License, which permits unrestricted use, distribution, and reproduction in any medium, provided the original author and source are credited. 